\title{
Multiaxial fatigue behavior of 2618 aluminum alloy
}

\author{
Benaïssa Malek ${ }^{*}$, Catherine Mabru and Michel Chaussumier \\ Université de Toulouse, Institut Clément Ader (ICA), UMR CNRS 5312, UPS/INSA/ISAE/ Mines \\ Albi, 3 rue Caroline Aigle, 31400 Toulouse, France
}

\begin{abstract}
The purpose of the present research project is to study multiaxial fatigue behavior of 2618 alloy. The influence of mean stress on the fatigue behavior under tension and torsion is particularly investigated. Fatigue tests under combined tensile-torsion, in or out of phase, as well as combined tensile-torsion-internal pressure tests have also been conducted. Multiaxial fatigue results are analyzed according to Fatemi-Socie criterion to predict the fatigue life.
\end{abstract}

\section{Introduction}

Aluminum alloys take the first rank in nonferrous materials and are the engineering materials of choice for several industrial applications; they are for instance widely used in aeronautic construction because of their good mechanical properties and low density.

Numerous fatigue studies concerning these materials are focused on uniaxial loading. However, the aeronautical parts usually experience multiaxial fatigue loading during service and previous studies $[1,2]$ showed that mean shear stress could have a detrimental effect on fatigue life. Evaluating fatigue life under complex loading conditions is therefore essential to understand the behavior of the component or the structure and to assess its safety and durability.

Very few studies dealing with the effect of mean shear stress on the fatigue lifetime of aluminum alloys have been done, but in fact, this effect is very important because it makes the fatigue life decreased $[1,2,3]$ and several components are subjected to unsymmetrical loading while in service.

Many authors reached the conclusion that mean shear stress does not affect the fatigue life $[4,5]$ as long as the maximum shear stress is below the yield strength. The effect of the mean shear stress is not clear in the high cycle fatigue, but become obvious in the low cycle fatigue [6].

\footnotetext{
benaissa.malek@isae.fr
} 
In addition, it has been demonstrated for an aluminum alloy from $2 \mathrm{xxx}$ series that fatigue life gradually reduces with increasing mean shear stress when this latter is lower than a threshold value [1,7].

In the current study, the purpose of the research project about 2618 alloy is to study its multiaxial fatigue behavior. The influence of mean stress on the fatigue behavior under tension and torsion is particularly investigated. Fatigue tests under combined tensiletorsion, in or out of phase, as well as combined tensile-torsion-internal pressure tests have also been conducted. It is important to note that research works with internal pressure loading is rare [8]. Multiaxial fatigue results are analyzed according to Fatemi-Socie multiaxial fatigue criterion to predict the fatigue life. Fracture surface observations and in particular crack initiation sites were also performed in order to broaden this analysis.

\section{Material and experimental procedures}

\subsection{Material}

The material used in the present study is 2618-T851 aluminum-copper alloy developed by Rolls Royce (RR58) and characterized by high mechanical characteristics and low density. The chemical composition and mechanical properties are respectively presented on table 1 and table 2 .

The material has been heated at $530^{\circ} \mathrm{C} \pm 5^{\circ} \mathrm{C}$ to dissolve some intermetallic particles such as $\mathrm{Al}_{2} \mathrm{CuMg}, \mathrm{AI}_{2} \mathrm{Cu}$ et $\mathrm{Al}_{7} \mathrm{Cu}_{4} \mathrm{Ni}[9,10]$, water quenched then tempered at $190^{\circ} \mathrm{C}$ (the maximal hardness is obtained at this temperature [11]). The material is deformed by tension and then quenched and tempered at $200^{\circ} \mathrm{C}$ during some minutes to give the mechanical properties cited in table 2.

Table 1. Chemical composition of 2618-T851.

\begin{tabular}{|c|c|c|c|c|c|c|c|c|c|}
\cline { 2 - 9 } \multicolumn{1}{c|}{} & $\mathbf{C u}$ & $\mathbf{F e}$ & $\mathbf{M g}$ & $\mathbf{S i}$ & $\mathbf{N i}$ & $\mathbf{T i}$ & $\mathbf{Z n}$ & $\mathbf{M n}$ & $\mathbf{A l}$ \\
\hline $\begin{array}{c}\text { atomic } \\
\mathbf{\%}\end{array}$ & $0,9-1,5$ & $0,4-0,6$ & $1,5-2$ & 0,2 & $0,2-0,6$ & 0,15 & $<0,1$ & $<0,15$ & Rest \\
\hline
\end{tabular}

Table 2. Mechanical properties of 2618-T851 alloy.

\begin{tabular}{|c|c|c|c|c|c|}
\hline $\begin{array}{c}\text { Young } \\
\text { modulus E } \\
(\mathbf{G P a})\end{array}$ & $\begin{array}{c}\text { Ultimate } \\
\text { tensile strength } \\
(\mathbf{M P a})\end{array}$ & $\begin{array}{c}\text { Tensile yield } \\
\text { strength }(\mathbf{0 , 2} \%) \\
(\mathbf{M P a})\end{array}$ & $\begin{array}{c}\text { Shear } \\
\text { modulus G } \\
(\mathbf{G P a})\end{array}$ & $\begin{array}{c}\text { Shear yield } \\
\text { strength }(\mathbf{0 , 2} \%) \\
(\mathbf{M P a})\end{array}$ & $\begin{array}{c}\text { Ratio } \\
\boldsymbol{\sigma}_{\mathbf{y}} / \tau_{\mathbf{y}}\end{array}$ \\
\hline 72 & 464 & 438 & 27 & 260 & 1,69 \\
\hline
\end{tabular}

For the microstructure, 2618-T851 alloy is characterized by the presence of many various intermetallic precipitates localized in grains and grain boundaries and divided in two types, the coarse particles $(\geq 1 \mu \mathrm{m})$ and hardened particles $(\leq 200 \mathrm{~nm})$ as shown in figure 1 . 


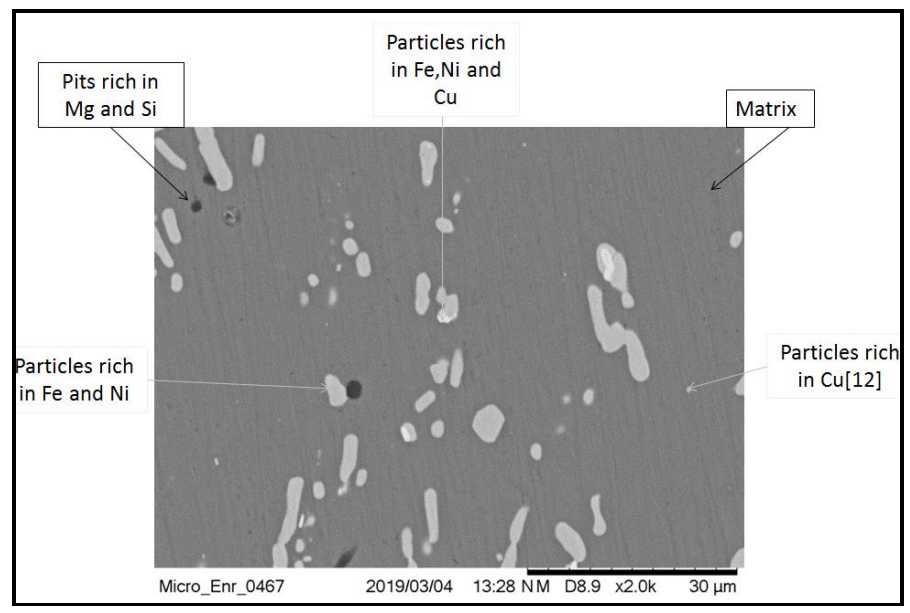

Fig. 1. Microstructure of 2618-T851 aluminum alloy.

\subsection{Fatigue tests}

In this study, all the load-controlled fatigue tests were carried out at room temperature by a special testing MTS-809 machine. The testing machine is hydraulic multiaxial fatigue machine that can combine tension, torsion, and cyclic internal pressure loading until 1200 bars.

Two different specimen geometries are used as shown in figures 4 and 5. One is the full cylindrical specimen (figure 2) used for tension and/or torsion loading, and the other is the hollow cylindrical specimen (figure 3 ) used for internal pressure loading.

The surface roughness is $0,8 \mu \mathrm{m}$ for all the specimens. It was shown in a previous study that surface roughness has no effect on fatigue life of 2618-T851 with different surface arithmetic roughness levels corresponding to general industrial values in tension and torsion [13].

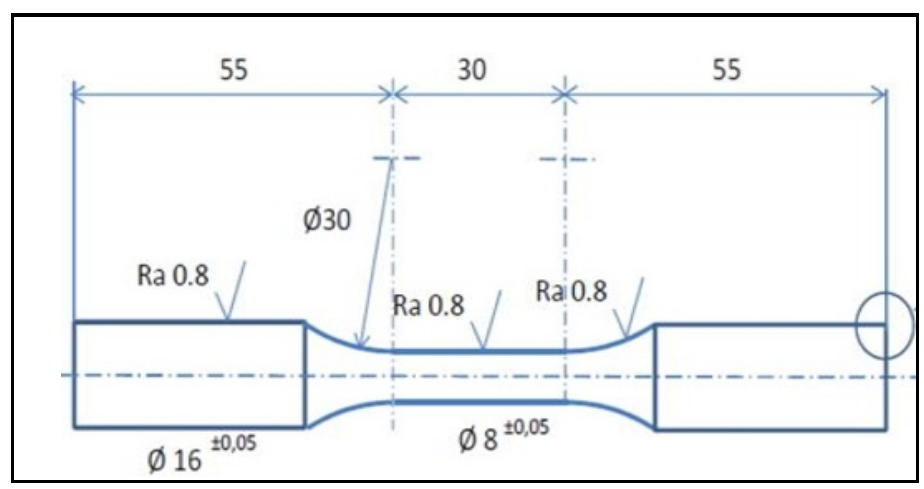

Fig. 2. Cylindrical specimen geometry (dimensions are in $\mathrm{mm}$ ). 


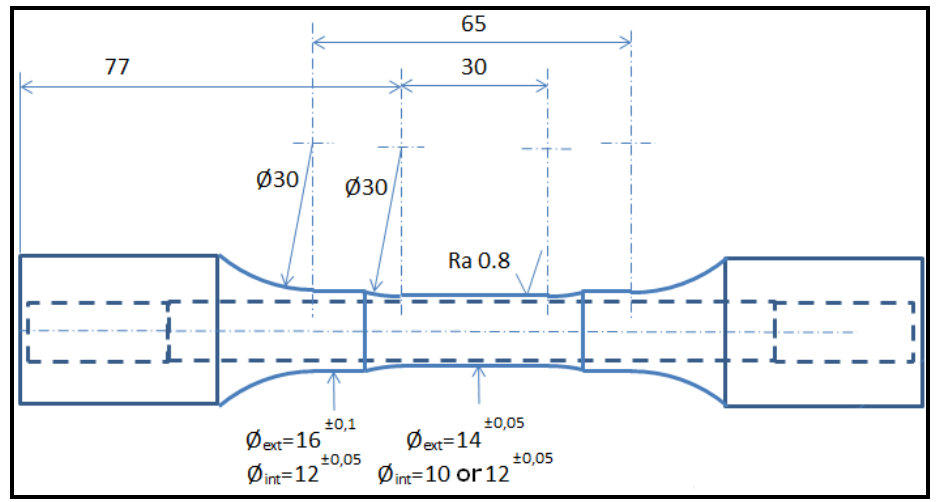

Fig. 3. Hollow cylindrical specimen geometry (dimensions are in $\mathrm{mm}$ ).

Uniaxial fatigue tests have been conducted under several stress ratios $(-2,-1$ and 0,1$)$ with a frequency of $10 \mathrm{~Hz}$, the variation of strain time dependency was determined using biaxial extensometer.

\subsection{Multiaxial stress states of hollow specimen}

When the internal pressure is applied, the stress state in cylindrical coordinates is given by the following equations:

$$
\begin{aligned}
& \sigma_{r}(t)=\frac{R i^{2} p_{i}(t)}{\operatorname{Re}^{2}-R i^{2}}\left(1-\frac{\mathrm{Re}^{2}}{r^{2}}\right) \\
& \sigma_{\theta}(t)=\frac{R i^{2} p_{i}(t)}{\operatorname{Re}^{2}-R i^{2}}\left(1+\frac{\mathrm{Re}^{2}}{r^{2}}\right) \\
& \sigma_{r \theta}(t)=0
\end{aligned}
$$

The variation of the three stresses along the radius ' $r$ ' is shown in figure 4 where the stress components coming from the analytical analysis and from finite element computing are compared. Figure 4 illustrates the perfect coherence between the analytical and the numerical models. 


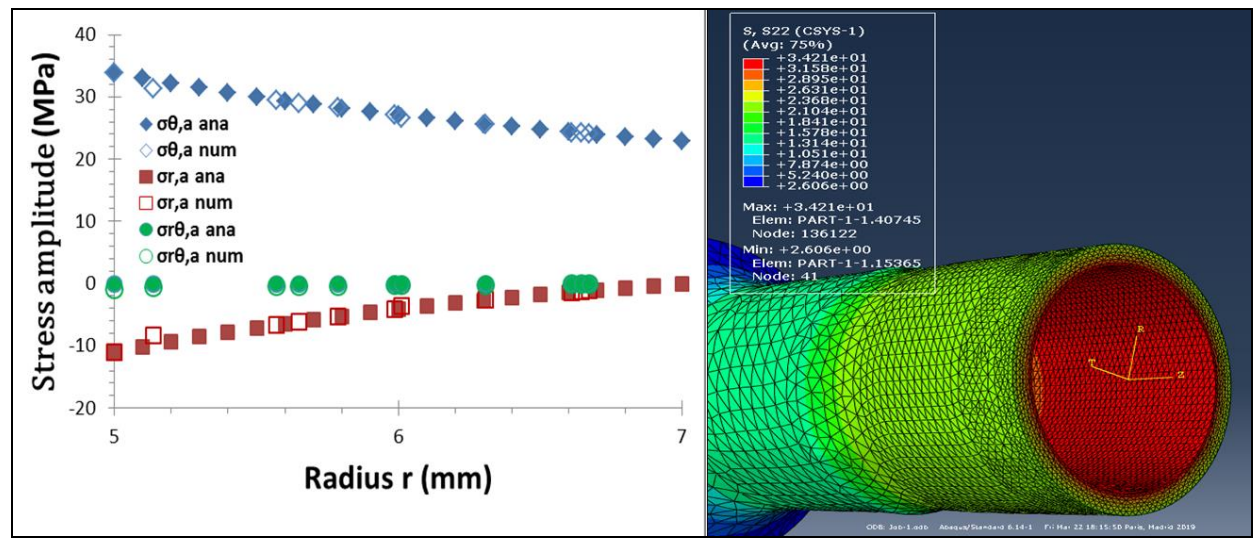

Fig. 4. Left side: variation of stresses (analytical and numerical) along the radius r. Right side: hoop stress. $\mathrm{P}_{\max }=244$ bars and $\mathrm{R}=0,1$.

Understanding the variation of hoop and radius stresses along the radius in the case of a loading including internal pressure is of high importance to fully determine the stress states during combined loading and, in particular the position of the critical plane with the maximum shear stress for example, as seen in the following section.

\section{Results and discussion}

\subsection{Effect of load ratio}

In a previous study, tensile tests conducted with a positive stress ratio $(0,1)$ and a negative stress ratio (-2) have shown that a positive mean stress makes the fatigue life decrease significantly [13]. This effect is well known and is observed for numerous metallic alloys [14].

Results for pure torsion fatigue tests are shown in figure 5. A positive mean shear stress reduces the fatigue life [2,3] even if the maximum shear stress is below the yield strength. This sensitivity is more important at low stress amplitude.

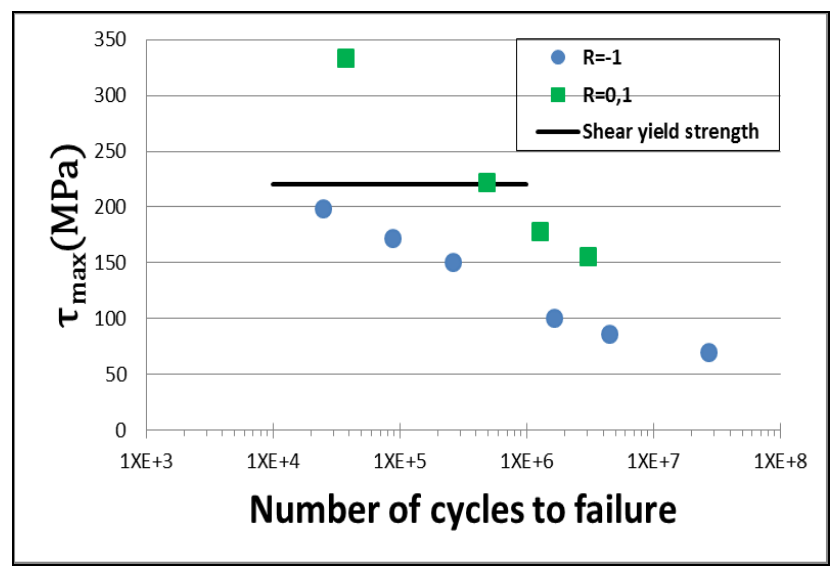

Fig. 5. Torsion S-N curve under different values of mean shear stress. 
From these results, it is clear that the effect of mean shear stress must be taken into account to estimate fatigue life under multiaxial stress states.

\subsection{Multiaxial loading results}

Multiaxial fatigue tests have been carried out under tension-torsion loading with different mean normal/shear stress in-phase and out-phase (Table 3) and under multiaxial cyclic loading including internal pressure in different cases (Table 4).

Results of pure tension and torsion tests and internal pressure with tension or torsion are illustrated in figure 6 . All the tests have been conducted with a stress ratio equal to 0,1 in each loading axe.

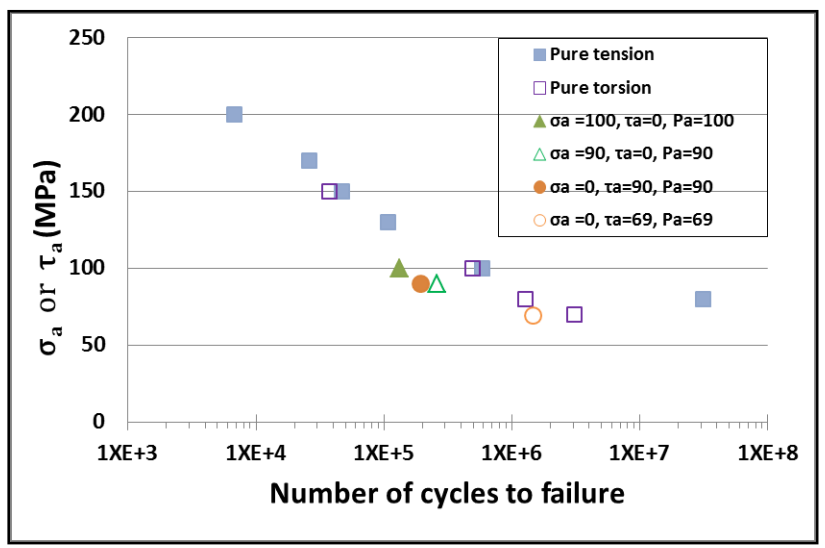

Fig. 6. Results of pure uniaxial tests and uniaxial tests combined with internal pressure; stresses are in $\mathrm{MPa}$ and pressure in bars, $\mathrm{R}=0,1$.

Table 3. Tension-torsion fatigue test results, $\mathrm{f}=10 \mathrm{~Hz}$.

\begin{tabular}{|c|c|c|c|c|c|}
\hline $\boldsymbol{\sigma}_{\mathbf{a}}(\mathbf{M P a})$ & $\boldsymbol{\tau}_{\mathbf{a}}(\mathbf{M P a})$ & $\boldsymbol{\sigma}_{\mathbf{m}}(\mathbf{M P a})$ & $\boldsymbol{\tau}_{\mathbf{m}}(\mathbf{M P a})$ & $\boldsymbol{\varphi}\left({ }^{\circ}\right)$ & $\mathbf{N}_{\mathbf{f}}(\mathbf{C y c l e s})$ \\
\hline 40 & 110 & 0 & 0 & 0 & $1,24.10^{6}$ \\
\hline 95 & 193 & 0 & 0 & 0 & $2.05 .10^{4}$ \\
\hline 150 & 70 & 0 & 0 & 90 & $2,81.10^{5}$ \\
\hline 150 & 70 & 0 & 0 & 0 & $2,64.10^{5}$ \\
\hline 40 & 110 & 0 & 0 & 90 & $1,17.10^{6}$ \\
\hline 137 & 97 & 0 & 0 & 0 & $1,36.10^{6}$ \\
\hline 150 & 70 & 0 & 85,55 & 0 & $9,95.10^{4}$ \\
\hline 150 & 100 & 0 & 122,22 & 90 & $7,42.10^{4}$ \\
\hline 150 & 70 & 183,33 & 0 & 90 & $3,36.10^{4}$ \\
\hline
\end{tabular}

Table 4. Multiaxial fatigue test results including internal pressure, $\varphi=0^{\circ}, \mathrm{f}=1 \mathrm{~Hz}$ and $\mathrm{R}=0,1$.

\begin{tabular}{|c|c|c|c|}
\hline $\boldsymbol{\sigma}_{\mathbf{a}}(\mathbf{M P a})$ & $\boldsymbol{\tau}_{\mathbf{a}}(\mathbf{M P a})$ & $\mathbf{P}_{\mathbf{a}}$ (bars) & $\mathbf{N}_{\mathbf{f}}$ (Cycles) \\
\hline 100 & 100 & 100 & $1,9357.10^{4}$ \\
\hline 69 & 69 & 69 & $1,13993.10^{5}$ \\
\hline 50 & 50 & 50 & $>10^{6}$ (Whitout failure) \\
\hline 90 & 0 & 90 & $2,586.10^{5}$ \\
\hline 100 & 0 & 100 & $1,3295.10^{5}$ \\
\hline 0 & 135 & 90 & 16 \\
\hline 0 & 90 & 90 & $1,95.10^{5}$ \\
\hline 0 & 69 & 69 & $1,4667.10^{6}$ \\
\hline
\end{tabular}


Results in Figure 6 show that for a given stress amplitude, the fatigue life is similar in tension and in torsion.

This is consistent with the case of cast aluminum alloys where the ratio $\left(\tau_{\mathrm{D}} / \sigma_{\mathrm{D}}\right)$ is usually close to $1,1[15]$ ( $\tau_{\mathrm{D}}$ and $\sigma_{\mathrm{D}}$ are respectively fatigue limits in torsion and tension).

Adding internal pressure to uniaxial loading (tension or torsion) reduces the fatigue life and it seems that this detrimental effect is similar whatever the type of uniaxial loading combined with internal pressure (similar fatigue life time for tests performed with internal pressure of 90 bars combined with tension or torsion loading with a stress amplitude of 90 $\mathrm{MPa})$.

The results of the others tests combining tension and torsion in phase and out of phase as well as tension-torsion- internal pressure in phase will be analyzed in the last section.

\subsection{Surface fracture analysis}

Fracture surfaces observations were made to identify the different modes of fracture under the various load paths. The main microscopic fracture features are a combination of ductile intergranular and transgranular fracture. When torsion is applied, some abrasion marks appeared in some regions.

Whatever the nature of the loading, in the high cycle fatigue, the fatigue cracks initiated on a single site at the surface, and a coarse precipitate is found at the initiation site, as shown in figure 7 . For two specimens tested in pure tension and broken over $10^{7}$ cycles, the cracks initiated in sub-surface ( $200 \mu \mathrm{m}$ and $700 \mu \mathrm{m}$ from the surface) on coarse grain.

It is also important to note that for hollow specimen tested with a loading including internal pressure, initiation sites were always on the outer surface, whatever the combinations and the values of the axial and/or shear stress amplitude.
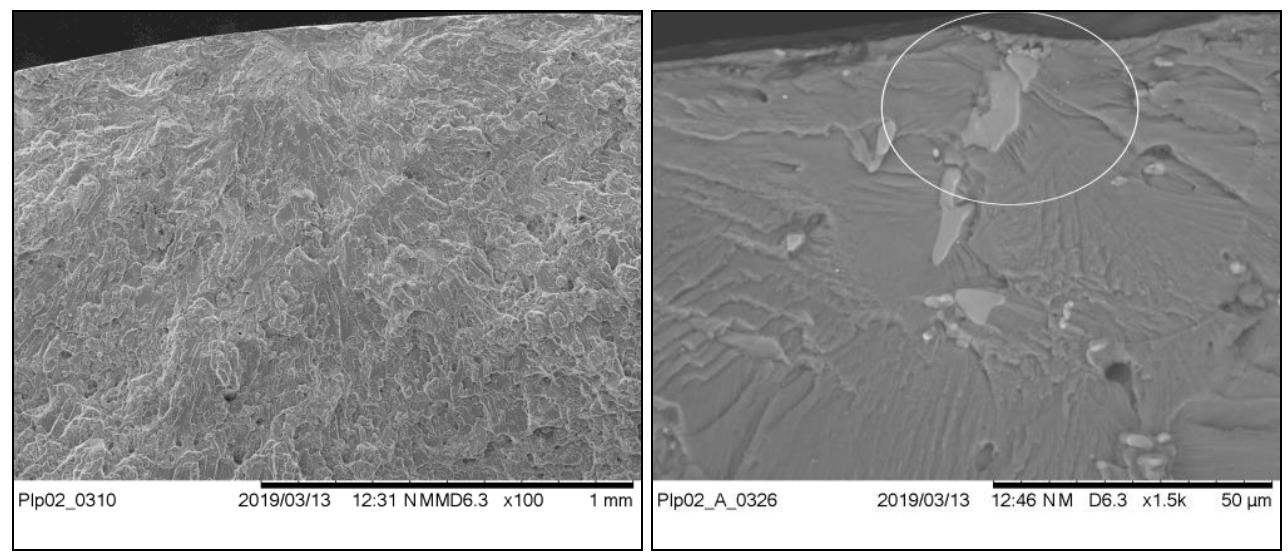

Fig. 7. Fatigue crack initiation site specimen tested in tension-internal pressure, $\sigma_{a}=100 \mathrm{MPa}, \mathrm{P}_{\mathrm{a}}=110$ bars and $\mathrm{R}=0,1$ in each loading axe. 


\subsection{Fatigue life predictions}

Critical plane-based fatigue life analyses were performed using Fatemi-Socie [16] concept to predict fatigue life for multiaxial loading. Fatemi and Socie defined the critical plane as the plane associated with the maximum shear strain amplitude.

Fatigue damage is supposed to be governed by the maximum shear stress amplitude $\left(\Delta \gamma_{\max } / 2\right)$ and the maximum normal stress $\left(\sigma_{\mathrm{n}, \max }\right)$ that are expressed on the model by the equation 4 below:

$$
\frac{\Delta \gamma_{\max }}{2}\left(1+\mathrm{k} \frac{\sigma_{\mathrm{n}, \max }}{\mathrm{S}_{\mathrm{y}}}\right)=\frac{\tau_{f}^{\prime}}{\mathrm{G}}\left(2 \mathrm{~N}_{\mathrm{f}}\right)^{\mathrm{bo}}+\gamma_{\mathrm{f}}^{\prime}\left(2 \mathrm{~N}_{\mathrm{f}}\right)^{\mathrm{co}}
$$

Where $S_{y}$ is the material monotonic yield strength; it serves to normalize the maximum normal stress in order to preserve a dimensionless term, $\mathrm{k}$ is a material constant depending on number of cycles to failure. $G$ is the shear modulus, $\tau_{\mathrm{f}}$ ' is the shear fatigue strength coefficient, $\gamma_{f}$ ' is the shear fatigue ductility coefficient, $b_{o}$ and $c_{o}$ are shear fatigue strength and shear fatigue ductility exponents, respectively.

In a first step, the identification of Fatemi-Socie approach parameters has been carried out from experimental tests obtained from uniaxial loading in tension $(\mathrm{R}=-2)$ and torsion $(\mathrm{R}=-$ 1), using the least square method on the whole set of fatigue data.

In a second step, results of multiaxial fatigue tests have been compared to fatigue life predictions given by Fatemie-Socie model as illustrated in figure 8 .

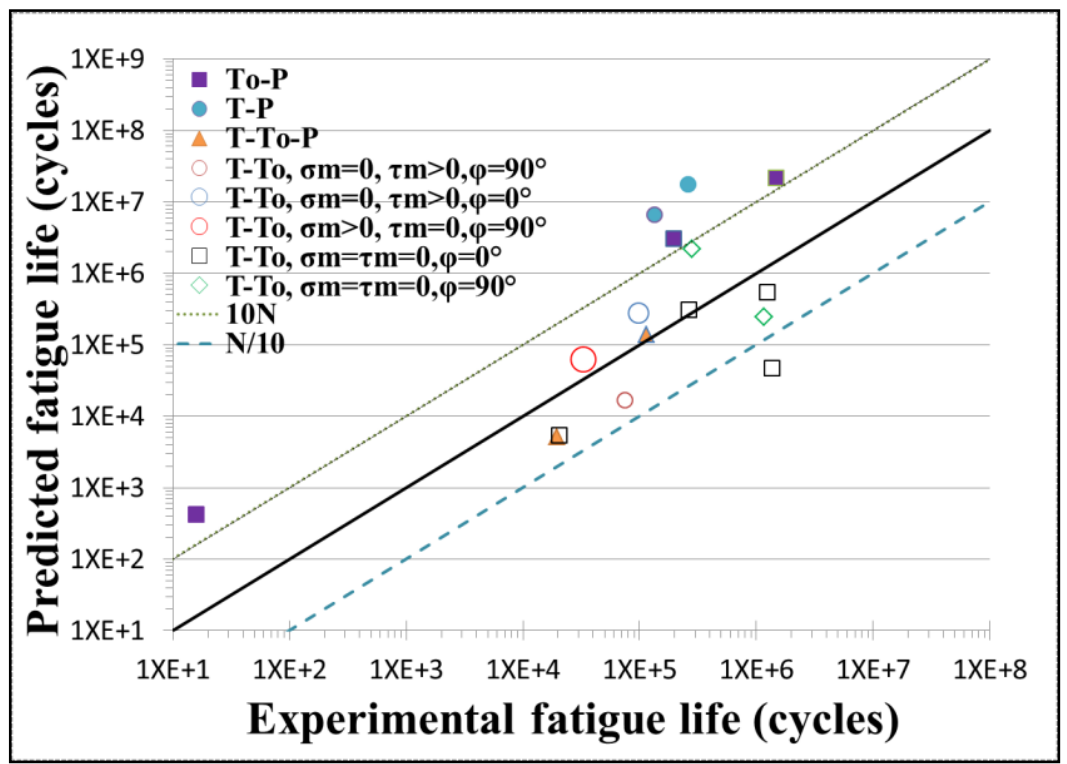

Fig. 8. Experimental vs Predicted fatigue life by FS model, 'T, To and P' refer, respectively, to tension, torsion and internal pressure, $\varphi$ is the phase angle.

A very large scatter of the results is observed in figure 8 . This shows that this criterion is not able to reproduce multiaxial fatigue behavior of 2618 aluminum alloy. In addition, in some cases, the model predicts that critical plane is in the inner surface. This is obviously contradictory to experimental observations that show systematic initiation on the outer surface. 


\section{Conclusion}

In the present study, it has been proved that a mean shear stress has a negative impact on the fatigue life of 2618 alloy.

In the high cycle regime, the cracks occur on surface from coarse intermetallic particles and at more than $10^{7}$ cycles, the cracks initiated on coarse grain in the sub-surface.

The predictions obtained using Fatemi-Socie model for this alloy are not in good agreement with experimental results. Other multiaxial fatigue criteria are currently under investigation.

\section{References}

[1] J. Zhang, Q. Xiao, X. Shi and B. Fei, Effect of mean shear stress on torsion fatigue failure behavior of 2A12-T4 aluminum alloy, Int Jour of Fatigue, 67: 173-182 (2014)

[2] K. Kluger, Fatigue life estimation for 2017A-T4 and 6082-T6 aluminium alloys subjected to bending-torsion with mean stress, Int Jour of Fatigue, 80: 22-29 (2015)

[3] K. Kluger and T. Lagoda, Fatigue life estimation for selected materials in multiaxial stress states with mean stress, Jour of Theo and Appl Mechan, 54: 385-396 (2016)

[4] L. Susmel, R. Tovo and P. Lazzarin, The mean stress effect on the high-cycle fatigue strength from a multiaxial fatigue point of view, Int Jour of Fatigue, 27: 928-943 (2005)

[5] H. Gadouini, Y. Nadot and C. Rebours, Influence of mean stress on the multiaxial fatigue behaviour of defective materials, Int Jour of Fatigue, 30: 1623-1633 (2008)

[6] I.V. Papadopoulos, P. Davoli, C. Gorla, M. Filippini and A. Bernasconi, A comparative study of multiaxial high-cycle fatigue criteria for metals, Int Jour of Fatigue, 19: 219-235 (1997)

[7] S. Xinhong, Z. Jianyu, X. Qingshan and F. Binjun, Multi-axial high-cycle fatigue failure behavior of 2A12-T4 aluminum alloy under torsion loading, The Tenth International Conference on Multiaxial Fatigue \& Fracture ICMFF10 (2013)

[8] T. Moroshita, Y.Takda, F. Ogawa, N. Hiyoshi and T. Itoh, Multiaxial fatigue properties of stainless steel under seven loading paths consisting, Theo and Appl Fract Mechan, 96: 387-397 (2018)

[9] Merchant HD, Kattamis TZ, Scharf G. Homogenization of aluminum alloys. Proceedings of the Homogenization and Annealing of Aluminum and Copper Alloys. Cincinnati, Ohio, October 12-13, 1987. The Metallurgical Society Publication: 1-53 (1987) [10] E.M. Elgallad, P. Shen, Z. Zhang and X.-G. Chen, Effects of heat treatment on the microstructure and mechanical properties of the AA2618 DC cast plate, Mat and Desi, 61: 133-140 (2014)

[11]: I. Özbek, A study on the re-solution heat treatment of AA 2618 aluminum alloy, Mat Charac, 58: 312-317 (2007)

[12] R.Viroulaud, Protection contre la corrosion des alliages d'aluminium par la conversion TCP : influence de la chimie de surface, Thèse de doctorat, Université Pierre et Marie Currie (2016)

[13] B. Malek, C. Mabru and M. Chaussumier, Study and modelling of anodized 2618 aluminum behavior subjected to multiaxial fatigue, MATEC Web Conf, 165 (2018)

[14] W. N. Findley, A theory for the effect of mean stress on fatigue of metals under combined torsion and axial load or bending, Engineering Materials research Laboratory, Division of Engineering (1958)

[15] I. Koutiri, D. Bellett, F. Morel, L. Augustins and J. Adrien, High cycle fatigue damage mechanisms in cast aluminium subject to complex loads, Int Jour of Fatigue, 47: 44-57 (2013)

[16] A. Fatemi and D. F. Socie, Fati Fract. Engng Mater. Struc,11: 149-165 (1998) 